\title{
Classification of agricultural risks of the digital economy
}

\author{
Mikhail Chernyakov ${ }^{1}$, Olesya Usacheva $^{1 *}$, and Sergey Gromov ${ }^{2}$ \\ ${ }^{1}$ Novosibirsk State Technical University, K. Marksa str., 20, Novosibirsk, 630073, Russia \\ ${ }^{2}$ RusAtom-international Network Private institution (Rosatom State Corporation), \\ Krasnopresnenskaya embankment, 12, Moscow, 119192, Russia
}

\begin{abstract}
The current state of the agricultural complex is characterised by a high degree of instability. This sector of the economy is affected by a significant number of factors, both climatic and human-made. Uncertainty in the state and development of the industry creates risks. The digitalisation of all sectors of the economy, on the one hand, is designed to reduce risks; on the other, it itself is the reason that creates new risks. A review of the scientific literature indicates an increased interest in this problem. However, there is a lack of experience in linking agricultural risks to the risks inherent in the digital environment. Our research is aimed not only at identifying risks in the agricultural complex in the conditions of digitalisation but also at their classification and determining the most significant in the agricultural complex. We suggested that the agricultural complex risks are associated with the risks of the digital economy. The justification of the hypothesis was carried out using mathematical operations with sets. The calculations made it possible as the most significant to distinguish technological and social risks in the agricultural complex, the levelling of which is possible using digital information platforms.
\end{abstract}

\section{Introduction}

Food safety issues have been quite alarming in the past several decades all over the world. A large number of papers were devoted to studying food safety. Notably, both the factors influencing food safety [1-4], and the influence of food safety on the country's national security [5] are studied. There is a dependence of the level of the political risk in agriculture on national food safety.

Agriculture is the basis for life sustenance in any country as it produces main food products for people. The present state of agriculture is characterised by high uncertainty; as a result, the sector has some risks that are connected with this uncertainty and require control. The key factors forming this uncertainty include the dependence on climatic conditions (floods, soil slips, draughts), distance of production structures from the centre, seasonal character of the production and payments for it, utilisation of a big part of the created products in the further production process, insufficient flexibility of the range of

\footnotetext{
* Corresponding author: Olesechka-nsk@yandex.ru
} 
products, an extended period of capital turnover, a technological process that is limited in time, and dependence of the operational procedures on biological characteristics of the assets.

It is important to say that many researchers note the necessity of systematisation of the risks inherent in agriculture, distinguishing the following typical ones: economic (entrepreneurial) risk, social risk, and the risk connected with natural factors [6].

The classification of risks from the point of view of their manageability: unavoidable risk (risk of loss due to natural disasters, emergencies, running the business in battle zones), that can be foreseen and insured; risk as a result of the uncertainty of the business processes (risk of loss due to unpredictable changes in the world market conditions in agriculture, achievements of scientific-and-technological advance), and unmanageable risk, that can only be avoided by a refusal from the business [6].

Developing the existing classification of risks, taking into account the industry specifics of agriculture, the following features are identified: "according to the sector" (the cropgrowing industry risks that are mainly connected with the climate, and the cattle-breeding industry caused by the anthropogenic factor); "according to the object where they arise" (risks connected with crops, livestock, and property of agricultural enterprises).

Special attention should be paid to risks that are based on a biological component, since they reflect changes in the processes of vital activity and growth of plants and animals (for example, the presence of infectious diseases). Also, in modern conditions, it is necessary to distinguish the information risk associated with the lack or distortion of information about the counterparties forming the chain: producer - processor - seller - consumer.

Agriculture is characterized by innovation risks, which can be distinguished by the innovation stages: research, commercial and technical risks (the stage of creation (upgrading) the novelty); natural environment and climatic, biological, technological, economic, organisational and managerial risks (stage of research, production and introduction of some innovation); commercial, biological and human resource risks (sale stage). The main risk factors are uncertainty and situations in which it is impossible to implement and obtain commercial results from design and technological developments.

Ingression of digital technologies into all sectors of the economy, including agriculture has resulted in increased publication activities. A significant number of papers of both Russian authors [6,7] and international ones [8,9] are devoted to the study of risks in agriculture.

It is noted that the agricultural sector of the Russian economy continues to lag behind in the development and implementation of new technologies, including digital technologies, in comparison with economically developed countries. Digital technologies have to be used by both the government to implement the functions of monitoring and control and by agricultural producers at all production stages. The digitisation process faces specific difficulties, such as the necessity to integrate digital systems in all business processes at the enterprise, to develop ready integrated solutions for the automation of all business processes, and to develop software. It also faces the lack of required specialists capable of applying IT technologies.

German researches consider mobile Internet the principal means for collecting information. They also note its leading role in the introduction of precision and smart agriculture. Also, they mention internet risks connected with the mobile Internet introduction in agriculture [10].

Greek scientists C. V., Popescu, M.-L., Bodislav, D. A., Oancea Negescu, M. D. put emphasis upon the necessity to study information risks that increase in connection with the digitisation of all economy sectors including agriculture. In particular, they point to the problem of ensuring transparency, information content and efficiency at all levels of 
agricultural enterprise management and the necessity to assess both benefits and losses caused by the risks of new technology introduction [11].

Romanian scientists G. Biali and P. Cojocaru used digital technologies for qualitative assessment of the flow slide risk in agricultural designation regions. The authors used the geographic information system (GIS) method that makes it possible to consider a combination of factors with spatial distribution (climate, geomorphology, seismic activity, sowing of different types of plants on one territory, etc.) in the assessment and monitoring of the slope instability risk. Based on the flow slide risk zoning, an opportunity appears to adopt a respective strategy for the management of this natural process, preventing by doing so the harmful and destructive social, ecological and economic consequences [12].

The risks caused by natural and climatic conditions are also studied by A. Ruda et al. They suggest studying the risk of drought in regions with the continental climate from the point of view of complicated landscape characteristics. The algorithm of detailed geographic modelling of the drought risk offered by the authors is based on the use of the latest meteorological data about the rainless season and preceding precipitation as well as on the digital model of the terrain and tiers of geographic data about the natural landscape characteristics and soil mantle. GIS is used as a set of tools [13].

The study of soil condition by Spanish scientists E. Pérez and P. García based on a combination of methods of satellite image digital processing and methods of digital modelling of the terrain relief helps find risk zones and allows a quick update of soil mapping [14].

A Turkish scientist A.S. Demirkesen studied flood risks using digital technologies by getting geoinformation from remote sensing data and interpreting flood risk levels in the settlements in the region and agricultural floodplains. Spatial distribution of flood risk zones was determined both with the use of present-day space data from the digital terrain model for the creation of maps illustrating the digital terrain model and a 3D end-to-end dynamic model of the region under study and with the use of extended thematic Landsat-7 cartographer plus a set of multispectral image data for the creation of land management and soil mantle types in the studied region. This analysis allowed determining the places that are exposed to flood risks most of all [8].

American researchers R. Chan, C. Baffaut, A. Thompson, and J. Sadler presented a USDA-NRCS (WI) soil vulnerability index calculation for the assessment of the intrinsical soil vulnerability and the risk they pose for the quality of the water used in the arable crops agriculture. This algorithm presents interest, first of all, for specialists in soil and water resource conservation. The assessment was done using three methods: professional judgement, comparison with the clay soil conductivity index (CCI) developed specifically for clayed soils and comparison with the model results. As a consequence, factors influencing soil vulnerability were assessed, and the comparison of the classified regions was made [15].

So we can observe the undoubted interest of researchers from different countries to risk assessment in agriculture in the conditions of the digital transformation of the economy. We try to determine the critical agricultural risks in the conditions of digital economy transformation. We try to determine key agrarian risks in digitisation conditions. As we see it, the research findings will be interesting to both agricultural enterprises and regulatory agencies from the point of view of risk management in this sector of the economy.

\section{Research technique}

To reduce time and labour costs of routine processing of monographs, publications, reviews, the cognitive technology methodology was used. Application of this technique allows the automation of the information retrieval from Internet sources and the selection of 
the most reliable data for assessment and analysis. The obtained information was analysed using the apriori ranking.

The retrieved information was ranked with the help of operations of prepositions algebra, mathematical logic and theory of sets operations.

\section{Research results}

Having represented the risks described in The Doctrine of Food Security, and a digital economy risk classification in the form of risk set matrix:

$\mathbf{R}_{\mathbf{d f s}}=$ (economic, technological, agroecological, foreign policy, health, social, infrastructural),

$\mathbf{R}_{\text {rde }}=$ (technological, political, economic, social, psychological).

Using the meet of sets operation ( $\mathbf{R}_{\mathbf{d f s}} \cap \mathbf{R}_{\mathbf{r d e}}$ ), we distinguish agrarian risks of food safety coinciding with digital economy risks and obtain a new set that can be called classification of principal agrarian risks in the digital economy that were placed in the set intersection area (Fig. 1).

$$
\left.\mathbf{R}_{\mathbf{b}}=\left(\mathbf{R}_{\mathbf{d f s}} \cap \mathbf{R}_{\mathbf{r d e}}\right)=\text { (technological, social, economic, political }\right) \text {. }
$$

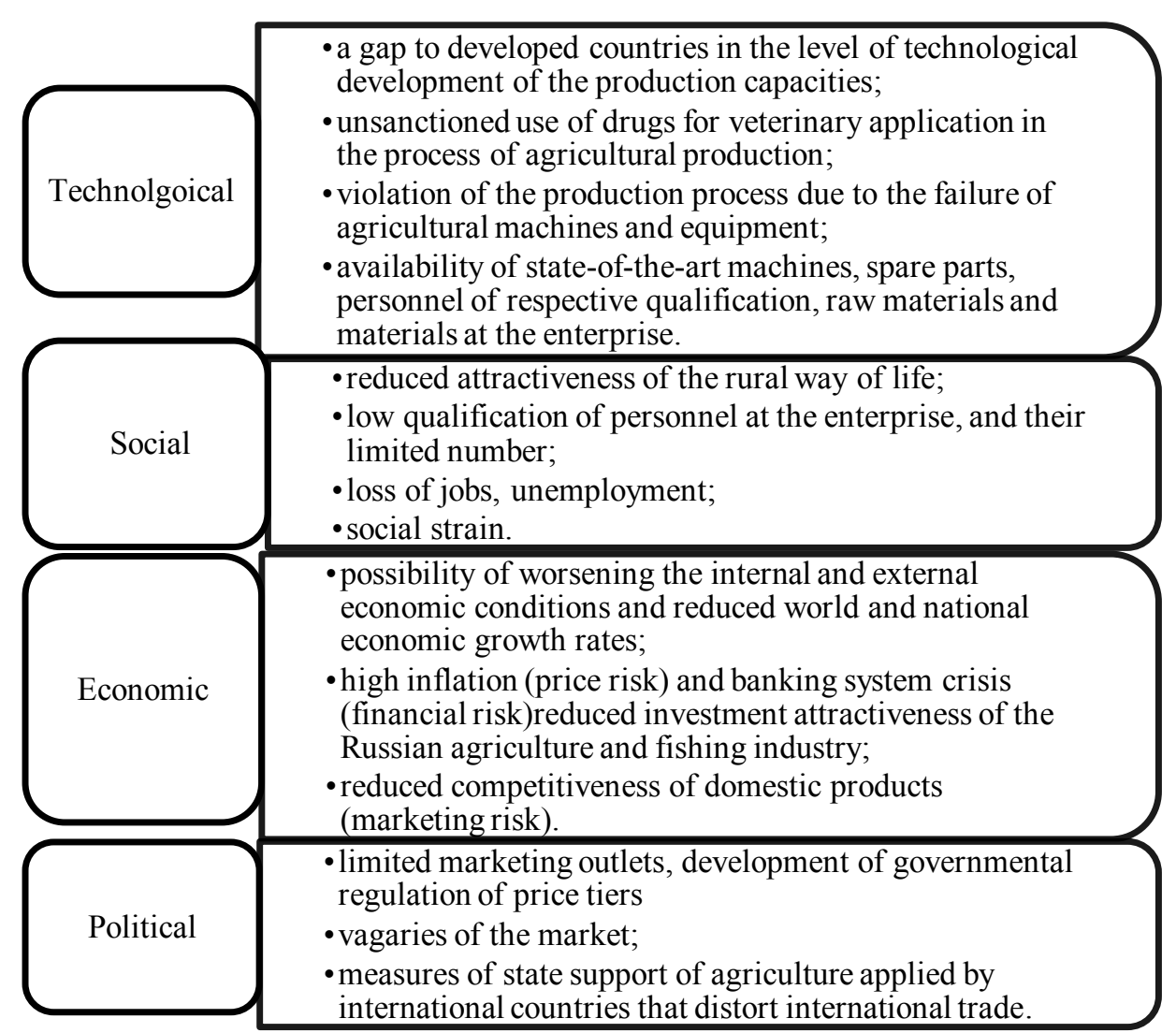

Fig. 1. Classification of key digital economy agrarian risks (DEAR) that are in the set intersection area. Developed by the author. 
Using the operation of different sets unification ([ $\left.\left.\mathbf{R}_{\mathbf{d f s}} \backslash \mathbf{R}_{\mathbf{r d e}}\right] \mathbf{U}\left[\mathbf{R}_{\mathbf{r d e}} \backslash \mathbf{R}_{\mathbf{d f s}}\right]\right)$, we determine the food safety risks that do not coincide with digital economy risks and get a new set that can be called as an additional classification of digital economy agrarian risks not included in the set intersection area (Fig. 2):

$$
\mathbf{R}_{\mathbf{b}}=\left(\left[\mathbf{R}_{\mathbf{d f s}} \backslash \mathbf{R}_{\mathbf{r d e}}\right] \mathbf{U}\left[\mathbf{R}_{\mathbf{r d e}} \backslash \mathbf{R}_{\mathbf{d f s}}\right]\right)=\left(\begin{array}{l}
\text { agroecological, health, infrastructural, } \text { psychological } \\
\text { and managerial }) .
\end{array}\right.
$$

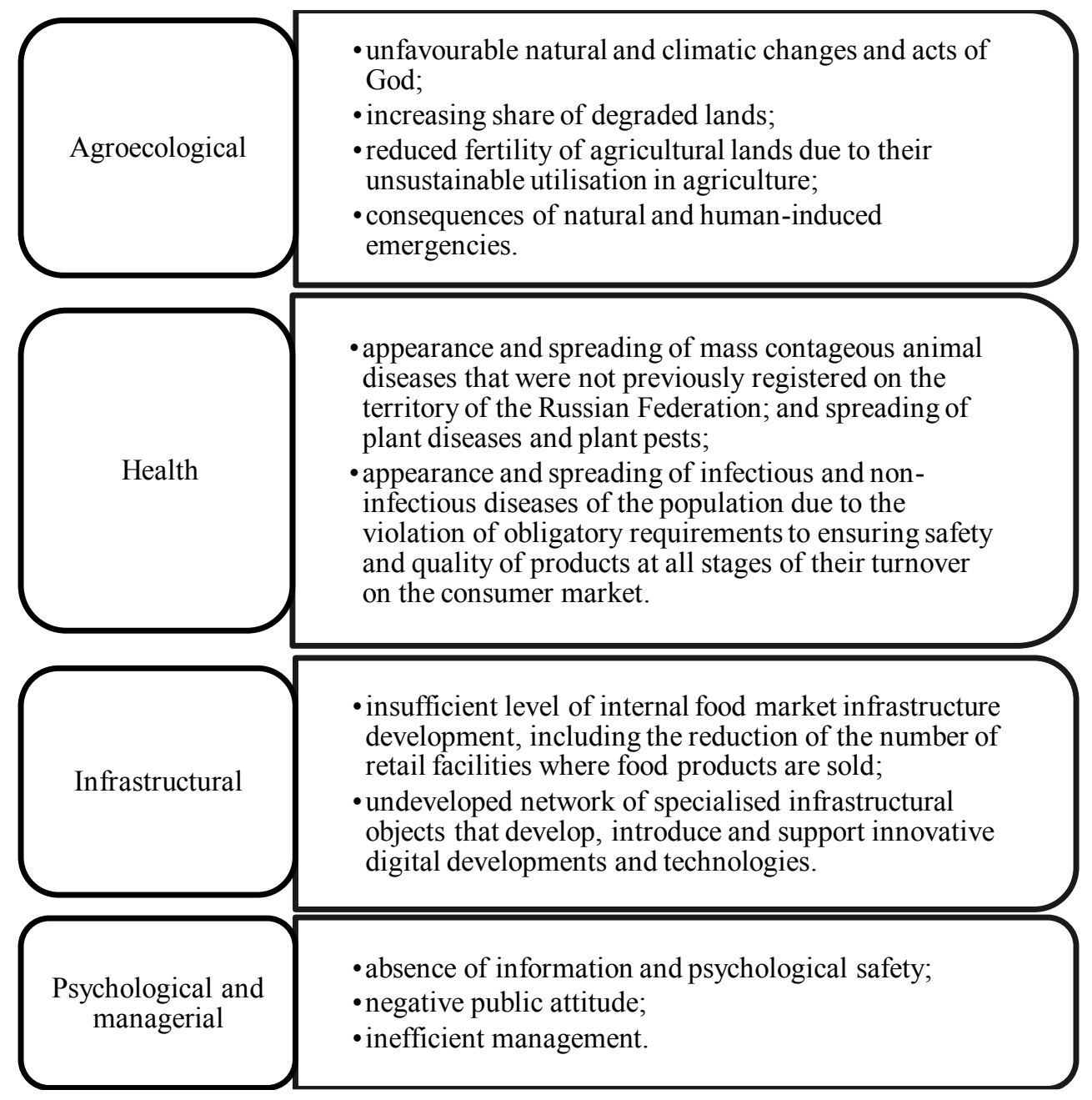

Fig. 2. Classification of additional DEAR, that are not included in the set intersection area. Developed by the author.

Classification of food safety risks in digitisation conditions in the initial set intersection area (2) that is given in Figure 1 and represented by set (3) can be referred to general elements for both initial sets, while the risks that were not included in Fig. 2 and are represented by set (4) - to particular risks. These new sets made us two types of general and particular DEAR (Fig. 3). 

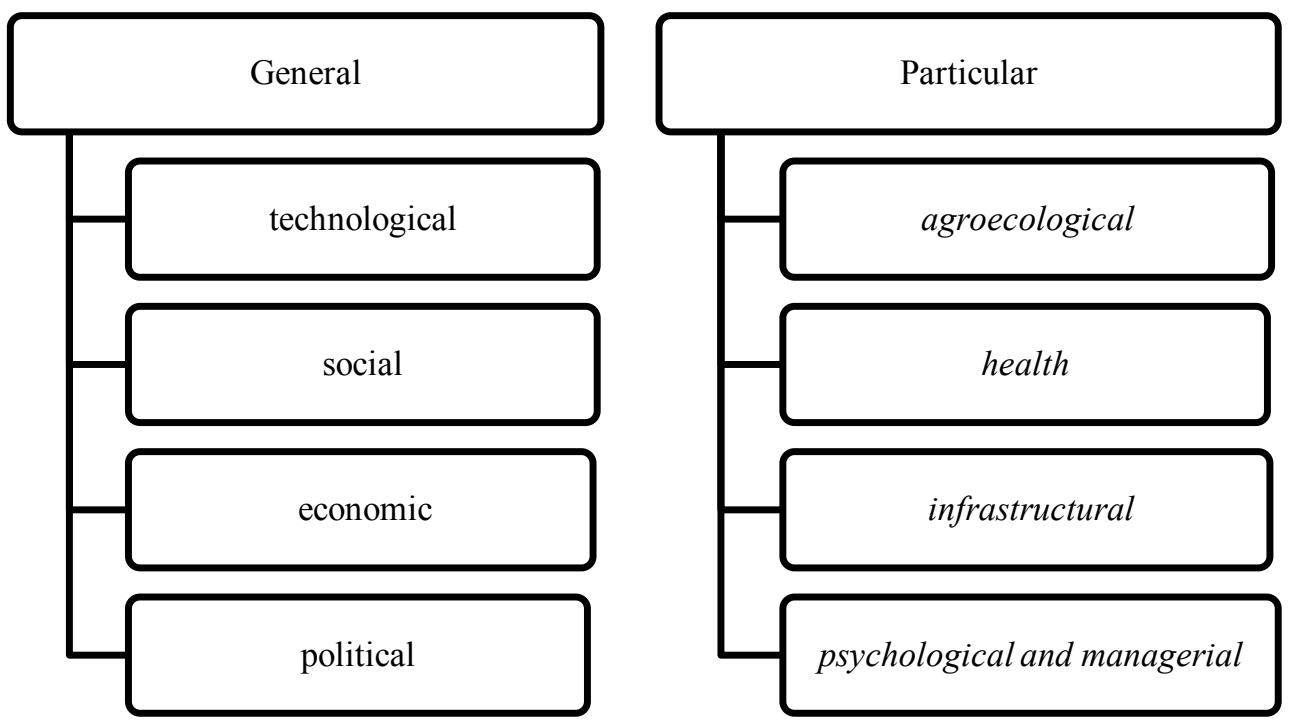

Fig. 3. Classification of DEAR according to manifestation types.

\section{Discussion of study results}

The technological risk becomes the main risk among the general risks in the agriculture digitisation conditions. If the information platforms are used efficiently, it can reduce other types of risks, and in the case of insufficient digital technological equipment, it can lead to their snowballing growth [7].

Social risk is the second one according to significance among the general risks. In the conditions of transformation into the digital economy, it can lead to the growth of underskilled workers unemployment with simultaneously growing demand in specialists capable of managing digital devices and technologies, which is especially challenging in rural areas [16].

The third most significant risk is the economic risk which, in the conditions of transformation into the digital economy, can worsen the internal and external economic situation and slow down the rate of the world and national economy growth, increase inflation and lead to a crisis in the banking system, reduce investment attractiveness of the domestic agrarian sector and decrease the competitiveness of domestic agricultural products.

Political risk can be called the fourth most significant risk. In the conditions of transformation into the digital economy, it can limit the potential of development of the domestic agrarian sector due to market fluctuations. Also, application of protectionist measures by foreign countries to increase state support of agriculture which disrupt international trade occupies this fourth place.

The division of general agricultural risks according to significance levels is very conditional, as they are tightly intertwined, and the appearance and growth of one of them can provoke the growth of another one or several ones.

Among the particular risks, agroecological and health risks should be noted. It is impossible to efficiently manage them in the conditions of a new economy without the use 
of state-of-the-art digital devices and technologies such as satellite and remote monitoring systems, large databases, etc.

Infrastructure risk should not also be ignored, as insufficiently developed infrastructure will lead not only to a reduced number of retail facilities selling food products, but to a difficult introduction and support of innovative digital developments and technologies.

Psychological and managerial risks include the dependency of economic agents on the Internet, worker displacement, lagging of the educational system from the demands of the digital economy, digital inequality, oligopolisation on the information market, reduction of governmental control over the digital economy, obtaining significant advantages by companies as compared to consumers due to the use of modern technologies for big data analysis, the supra-national character of the digital economy and the formation of a global network market for goods and services, reduction of possibilities for the implementation of protectionist measures aimed at national producer protection and import phase-out, and cybercrime growth.

Agricultural insurance can be acknowledged as the most efficient method of agricultural risks management method in the world; in the Russian Federation, it is poorly developed (less than $2 \%$ of planting acreage is insured in the Russian Federation as compared to over $85 \%$ in US or Canada).

\section{Conclusion}

Due to its specific functioning, agriculture is continuously influenced by some risks. The study determined the interconnection of the risks traditionally inherent to the agrarian complex with some risks arising in the conditions of economy digitisation. Agrarian risks of food safety coinciding with digital economy risks were determined using the method of sets unification. The use of operations with sets allowed distinguishing a new characteristic of the risk type classification according to their manifestation - they were divided into general and particular risks. Particular risks include such agrarian risks of the digital economy as agroecological, health, infrastructural and psychologic and managerial. It was determined that the most significant risk as refers to its effect on the sector is the general technological risk that can be controlled and regulated in the conditions of a digital landscape. It is necessary to take into account the conditionality of the risk division into general and particular ones, as well as their ranking as they are interconnected: the formation and growth of one type of risk can provoke a more substantial impact of other risks on agriculture.

\section{Reference}

1. S. Tandon, T. Vishwanath, Journal of World Developmen, June, 104922 (2020), doi:10.1016/j.worlddev.2020.104922

2. T. Wegenast, J. Beck, Journal of World Development, June, 104921 (2020), doi:10.1016/j.worlddev.2020.104921

3. A. I. Ogunniyi, G. Mavrotas, K. O. Olagunju, et al., Journal of World Development, June, 104752 (2020) doi:10.1016/j.worlddev.2019.104752

4. M. Mykolaichuk, N. Mykolaichuk, Baltic Journal of Economic Studies, 3(5), 304-310 (2017), doi:10.30525/2256-0742/2017-3-5-304-310

5. I. K. McDonough, M. Roy, P. Roychowdhury, Review of Economics of the Household, 18, 387-412 (2020), doi:10.1007/s11150-019-09456-z 
6. A. Alekseev, T. Kruzhkova, E. Kot, et al., International Transaction Journal of Engineering, Management, \& Applied Sciences \& Technologies, 11(10), 11A10Q, 111 (2020), doi: 10.14456/itjemast.2020.200

7. M. Chernyakov, M. Chernyakova, Journal of Corporate Finance Research, 12(4), 99109 (2018), e-journal: www.cfjournal.hse.ru, ISSN 2073-0438

8. A. C. Demirkesen, Arabian Journal of Geosciences, 9(3), 189 (2016), doi: $10.1007 / \mathrm{s} 12517-015-2263-\mathrm{z}$

9. J. Grashuis, J. Franken, Journal of Co-Operative Organization and Management, 8(2), 100-119 (2020), doi: 10.1016/j.jcom.2020.100119

10. M. Michels, W. Fecke, J.-H. Feil, et al., Agribusiness, 36(2), 192-207 (2020), doi: 10.1002/agr.21635

11. C.-V. Radulescuu, M.-L. Popescu, M. D. O. Negescu, D. A. Bodislav, European Journal of Sustainable Development, 8(5), 75, (2019), doi: 10.14207/ejsd.2019.v8n5p75

12. G. Biali, P. Cojocaru, Informatics, Geoinformatics and Remote Sensing Conference Proceedings, SGEM, 3, 579-590 (2016), URL: https://apps.webofknowledge.com/full_record.do?product=WOS\&search_mode=Gener alSearch\&qid=3\&SID=E6F8tcwlSqGjCeIM28A\&page $=1 \&$ doc $=1$

13. A. Ruda, J. Kolejka, K. Batelková, Pure and Applied Geophysics, 174(2), 661-678, (2017), doi:10.1007/s00024-016-1296-X

14. E. Pérez, P. García, Agriculture, 6(1), 7 (2016), doi: 10.3390/agriculture6010007

15. R. Chan, C. Baffaut, A. Thompson, J. Sadler, CATENA, 148, 185-194 (2017), doi: 10.1016/j.catena.2016.03.009

16. M. K. Chernyakov, Advances in Economics, Business and Management Research, 81, 373-378 (2019) 